Original article

\title{
İlkokul Öğrencilerinin Hava Durumu Sembollerini Algılama Düzeyi (TRT Çocuk Kanalı Örneği) ${ }^{1}$
}

\section{Primary School Students' Perception of Weather Symbols (TRT Kids Channel Example)}

\author{
Salih Ceylan a, Yaşar Özmen b \& Hüseyin Mertol c, * \\ a Department of Elementary School Teacher Education, Faculty of Education, Mehmet Akif Ersoy University, Burdur, Turkey \\ ${ }^{\mathrm{b}}$ Ministry of Education, Isparta, Turkey \\ 'Department of Turkish and Social Science Education, Faculty of Education, Süleyman Demirel University, Isparta, Turkey
}

\section{Özet}

Bu çalışmanın amacı, ilkokul 3. sınıf öğrencilerinin hava durumunu simgeleyen sembolleri algılama düzeylerini tespit etmektir. Bu amaç doğrultusunda araştırmanın çalışma grubunu Isparta-Merkez İıçesinde bulunan Hafız İbrahim Demiralay İlkokulu 3-D sınıfı öğrencileri oluşturmuştur. Araştırma kapsamında 29 öğrenci ile çalışılmıştır. Bu çalışmada veri toplama araçlarından yarı yapılandırılmış görüşme formu ile veriler toplanmış. TRT Çocuk kanalında yayınlanan hava durumu bültenini izleme durumlarına göre ön test ve son test uygulaması yapılmıştır. Araştırma sonuçlarına göre öğrencilerin yaz mevsimi hava durumu grafiklerine ilişkin bilgi düzeylerinde anlamlı artış meydana gelirken, kış mevsimi hava durumu grafiklerine ilişkin bilgi düzeylerinde herhangi bir değişim görülmediği, hatta bazı grafiklere ilişkin bilgi düzeylerinde anlamlı azalma meydana geldiği görülmüştür. İlkbahar ve sonbahar mevsimi sembolleri ise yaz ve kış mevsimi sembolleri içinde belirtilmiştir. Bu noktada ilkokul öğrencilerinin hava durumu grafiklerine iliş̧in bilgi düzeylerinin geliştirilmesine yönelik farklı eğitim programları uygulanabilir. Farklı eğitim programlarının ilkokul öğrencilerinin hava durumu sembolleri hakkındaki bilgi düzeyleri üzerine etkilerinin ele alındığı benzer çalışmalar yapılabilir. Böylece öğrencilerin hava durumu sembolleri konusundaki bilgi düzeylerini geliştirmeye yönelik yeni modeller ortaya konulabilir.

Anahtar Kelimeler: Algılama, Görsel Okuma, Hava Durumu Sembolü, Medya, Öğrenci.

\section{Abstract}

The aim of this study is to determine the levels of perception of primary school 3rd grade students symbolizing the weather. In line with this purpose, the study group of the research consisted of 3-D students of Hafız Ibrahim Demiralay Primary School in Isparta-City Center District. Within the scope of the research, 29 students were studied. In this study, data was collected through semi-structured interview form from data collection tools. Pretest and posttest were performed according to the weather bulletin monitoring status published on TRT Children's channel. According to the results of the research, while there was a significant increase in the knowledge levels of the students regarding the summer season weather graphics, there was no change in the level of information related to the winter season weather graphics, and even there was a significant decrease in the level of knowledge related to some graphics. Spring and autumn season symbols are indicated in the summer and winter season symbols. At this point,

\footnotetext{
* Corresponding author:

Hüseyin Mertol, Department of Turkish and Social Science Education, Faculty of Education, Süleyman Demirel University, Isparta, Turkey. Email: huseyinmertol@sdu.edu.tr

${ }^{1}$ Bu çalışma 2020 yıında Burudur Mehmet Akif Ersoy Üniversitesi Eğitim Bilimleri Enstitüsü İlköğretim Anabilim Dalı Sınıf Öğretmenliği Programında yapılmış olan 'ilkokul 3.sınıf öğrencilerinin görsel medyaya yayınlanan hava durumunu simgeleyen sembolleri algılama düzeyi’ adlı yüksek lisans tez çalışmasından alınmıştır.
} 

weather graphics. Similar studies can be conducted in which the effects of different education programs on the knowledge levels of primary school students on weather symbols are discussed. Thus, new models can be introduced to improve students' level of knowledge about weather symbols.

Keywords: Perception, Visual Reading, Weather Symbol, Media, Student.

Received: 11 February 2020 * Accepted: 20 March 2020 * DOI: https://doi.org/10.29329/ijiape.2020.239.2

\section{GİRIŞ}

Her şeyin hızla ve çokça değiştiği bir çağda yaşıyoruz. Bu değişiklik, geleneklerimizde, davranışlarımızda, inanç ve tutumlarımızda, dini algıda, bakış açımızda kendisini son derece yoğun hissettiriyor. Bireysel ve toplumsal hayatımızda oldukça rahat görülen bu farkl1lıklar içerisinde en dikkat çekici etkenlerden biri kuşkusuz medyadır (Geçer, 2013). İlk 1920’lerde kullanılmaya başlayan medya terimi Latincede ortam, araç anlamı taşıyan “medium” sözcügünün çoğulundan türetilmiştir. Medya, iletişim ortamı TDK sözlügüne göre ise iletişim kaynakları olarak ifade edilmektedir. Genel bir ifadeyle medya kavramı kitle iletişim araçları (internet, TV, radyo, dergi ve gazete) şeklinde nitelendirmek mümkündür (RTÜK, 2007).

Öğrenme döneminde çocuk öncelik olarak ailesiyle iletişim durumundadır (Akçalı, 2009). Aile içerisinde yetişen, olgunlaşan ve öğrenen çocuk, toplum içerisinde de değişir ve şekillenir. Çocuğun gelişimini etkileyen diğer önemli faktör medyanın etkisi kaçınılmaz bir durumdur (Ertürk, 2011). Medya denildiğinde ilk olarak zihinde canlanan televizyondur. Televizyonun genel olarak işlevleri haber verme, eğlendirme ve eğitme, farklı tür ve amaçlarla hazırlanan programlarla ses, hareket ve renk unsurlarını bir araya getirip sürekli iletiler göndererek gerçekleştirmektir. Modernleşme sürecinin temel tanımlayıcı araçlarından sayılan medya, televizyon içinde yer alan çok sayıdaki kanalıyla oturma odalarının başmisafiri haline gelmiştir. (Akçalı, 2014).

Bilgi biliminin yeni yönetim merkezi televizyondur. Küçük yaştaki çocuklar bile TV seyretmekten uzaklaştırılamazlar. Yoksulluğun en kötü şartları dahi televizyondan vazgeçmek için bir neden değildir. En iyi eğitim sistemi dahi televizyonun belirleyiciliğinden kurtulamaz. Asıl önemli olan ise, kamuoyunu ilgilendiren hiçbir konu (spor, bilim, din, eğitim, haber, politika) televizyonun ilgi alanı dışında kalmaz. Farklı bir deyişle, toplumun bu konuları algılama şekli tümüyle televizyonun yönlendirmeleri ile şekillenmektedir (Postman, 1985). Kitle iletişim kaynaklarının gelişim evreleri ve insanlara erişebilirlikleri dikkate alındığında, hiç biri televizyonun gücüne, özelliklede kısa bir süre içerisinde ulaşamamıştır (Kocadaş, 2005).

Günümüzde akıllı telefon, televizyon, bilgisayar vb. teknolojik araçlar ile bulunduğumuz yer ile ilgili hava durumu hakkında kısa sürede bilgi sahibi olunmaktadır. 2015 y1lı itibariyle Türkiye'de 
televizyon programcılığ ve yayın faaliyetleri olarak 481 kurum, radyo yayıncılığ olarak 787 kurum toplamda ise programcılık ve yayıncılık faaliyetleri yapan 1268 kuruluş vardır (TUIK, 2015). Medya kanalların birçoğu yayın kuşaklarında hava durumu bültenlerine yer vermektedir. Hava durumu bültenlerinde hava olaylarını betimlemek için çeşitli görseller kullanılmaktadır.

Görsel, gerçek veya hayali olsun fark etmeksizin orijinal bir modelden ortaya çıkan görüntüdür. Farklı bir deyişle görsel, bir gerçeğin taklit edilmesi, gerçek olmayan bir şeyi tanımamızı sağlayan görüntü, bir obje veya işaretin genel sunumudur. Görseller aracılığı ile zihinsel görüntüler yaratmak ve bir takım olayları zihin boyutunda canlandırmak son derece kolaydır. Görsel okuma evresi, zihni düzenleyen ve yapılandıran bir evredir. Bu evrede öğrenciler bir kavram veya konuya ilişkin zihinsel görüntülerini daha iyi düzenler ve yapılandırırlar (Güneş, 2013).

İşte bu çalışmada ilkokul üçüncü sınıf öğrencilerinin görsel medyada yer alan hava durumu sembollerini algılamaları belirlenmeye çalışılmıştır.

\section{YÖNTEM}

Araştırmada Nitel ve Nicel veriler ele alınarak karma yöntem kullanılmıştır. Nitel verilerin toplanmasında uzman görüşü alınarak oluşturulmuş olan öğrenci gözlem formundan yararlanılmış. İlk olarak öğrenci grubuna yaz dönemi ve kış dönemi sembollerinden oluşan ön test uygulaması farklı günlerde yapılmıştır. Velilerden yazılı onay alınarak 15 gün süreyle TRT Çocuk kanalında yer alan haber kuşağındaki hava durumu bültenini çocukların izlemesi istenmiştir. İzledikleri her günün sonunda veli ile öğrenci işbirliği yapılabileceği bilgisi verilmiştir ve 15 günün sonunda son test uygulanmıştır. Ön test ve son testte alınan yazılı cevaplar araştırmacı tarafından bilgisayar ortamına aktarılarak, 3 alan uzmanı tarafından puanlaması yapılmış, puanlamanın güvenirliğine ilişkin ise Cronbach Alfa katsayısı değeri 0.829 olarak hesaplanmıştır. Verilerin analizi, SPSS Version 22 programı ile yapılmıştır. Verilerin çözümlenmesinde, içerik analizi yönteminden yararlanılmıştır.

\section{Araştırma Deseni}

Bu çalışmada öğrencilerin TRT Çocuk kanalında yayınlanan hava durumu sembollerini algılama düzeylerini ölçmek için nitel ve nicel karma model özelliği taşımaktadır.

\section{Çalışma Grubu}

Araştırmanın çalışma grubunu Isparta-Merkez İlçesinde bulunan Hafız İbrahim Demiralay İlkokulu 3-D sınıfı oluşturmuştur. Araştırma kapsamında 29 öğrenci ile çalışılmıştır.

\section{Veri Toplama Araçları}

$\mathrm{Bu}$ çalışmanın verileri araştırmacı tarafından hazırlanıp uzman görüşü alınarak geçerlilik ve güvenilirliği yapılarak geliştirilen "TRT Çocuk Kanalında Yayınlanan Hava Durumu Sembollerinin Algılanma Düzeyi Görüşme Formu” ile yapılmıştır. 
Literatür ve ön görüşmelere dayalı olarak araştırmacı tarafından hazırlanan bu görüşme formu, konuyla ilgili uzman (program geliştirme ve ölçme değerlendirme) görüşüne sunulmuş, gerekli düzenlemeler ve eklemeler yapıldıktan sonrada uygulamaya hazır hale getirilmiştir. Verilerin sağlıklı olabilmesi için uygulama yapılacak okul ziyaret edilmiştir. Uygulama öncesi sınıfın öğretmeni ile yüz yüze iletişime geçilerek yarı yapılandırılmış görüşme formu ile ilgili bilgi verilmiştir. Öğrenci velilerine yazılı bilgilendirme yapılması sağlanmış ve yazılı onayları alınmıştır. Velilerin yazılı onayı alındıktan sonra sınıf öğretmeni ile uygulama için uygun tarih kararlaştırılmış ve bu kapsamda randevu alınan tarihte öğrencilere yarı yapılandırılmış görüşme formunun dağıtımı sağlanmıştır. Katılımcı öğrenciler görüşme formunda yer alan sorularla ilgili görüşlerini el yazıları yazmaları istenmiş görüşme yapılan formda öğrenci kimliği ile ilgili bir bilgiye yer verilmemiştir.

$\mathrm{Bu}$ araştırma için gerekli veriler, uzman görüşüne başvurularak geliştirilen ve açık uçlu sorularda oluşan yarı yapılandırılmış görüşme formu ile alınmıştır. Formun içeriğinde yaz dönemi için 9 hava durumu sembolü ve her sembol için 4 sorudan (Nedir?, Nasıl?, Nerede? ve Ne zaman?), kış dönemi için 17 hava durumu sembolü ve her sembol için 4 sorudan ( Nedir? Nasıl? Nerede? ve Ne zaman? ) oluşmaktadır.

\section{Verilerin Analizi}

Araştırmanın Nitel verileri ön test ve son test sorularının cevaplarını içerir. Yarı yapılandırılmış görüş̧me formunun ön testi öğrencilere uygulandıktan sonra çocuklardan 15 gün süreyle TRT Çocuk kanalındaki haber bülteni izlemeleri istenmiştir. 15 gün süre zarfında velilerin çocukların gelişim sürecini izlemeleri sağlanmıştır. Her günün sonunda velilerden "Veli Görüşme Formu” nu yazılı olarak değerlendirmeleri istenmiştir. TRT Çocuk kanalının 15 gün izledikten sonra sınıf ortamında öğrencilere son test uygulanmış ve süreç tamamlanmıştır.

Ön test sorularının ve son test sorularının cevapları içerik analizi uygulanarak değerlendirilmiştir. İçerik analizi teknikleri, bir söylemi anlamada ve yorumlamada, öznel etkenlerden kurtulmayı sağlamak amacını taşımaktadır. Söylemin görünen, kolayca yakalanan, sergilenmiş ve ilk bakışta algılanan içeriği yerine, gizil, üstü örtülü içeriğini ortaya çıkarmayı sağlamaktadır. Dolayısıyla içerik analizi, mesajda, bireyi görünmeden etkileyen öğelerin belirlenmesine yönelik "ikinci bir okuma"dır (Bilgin, 2006).

Yarı yapılandırılmış görüşme formlarına yazılan görüşler toplanıp bilgisayar ortamında yazıya dönüştürülerek kaydedilmiştir. Görüşme sürecinde elde edilen yazılı dokümanların çözümlenmesinde ilgili literatür dikkate alınarak okunmuştur. Ayrıca araştırmada elde edilen verilerin değerlendirilmesi esnasında araştırmaya katılan öğrenciler Ö1,Ö2, ....Ö29 şeklinde kodlanmıştır. Yarı yapılandırılmış görüşme formunda öğrencilere yöneltilen yaz dönemi ve kış dönemi olmak üzere toplam 104 açık uçlu soruya verilen cevaplar 3 alan uzmanı tarafından puanlanmıştır. Araştırma kapsamında içerik analizi 
yöntemine başvurulmuştur. Görüşme formunun güvenirliğine ilişkin Cronbach Alfa katsayısı değeri katsayısı 0.829 olarak hesaplanmıştır.

Eğer elimizde her hangi bir değişken ile ilgili olarak bir durum öncesi ve sonrası ölçüm değerleri varsa; örneğin verilen bir eğitim sonrasında grupların tutum, düşünce veya algılamalarında bir değişikliğe neden olup olmadığı araştırılıyor ise kullanılacak olan istatistiksel yöntem t-testidir (Sipahi vd 2008 s134). Yapılan bu çalışmada elde edilen verilerin analizinde SPSS 22.0 programından yararlanılmıştır. Öğrencilerin yaz ve kış grafiklerinden altıkları ortalama ön test ve son test puanların karşılaştırılmasında $\mathrm{T}$ testi kullanılmıştır.

\section{BULGULAR}

Tablo 1. Yaz Mevsimi Sembollerinden "Sel Olayı Nedir ?" Sorusuna Verilen Cevaplar

\begin{tabular}{llll}
\hline Ön Test Cevapları & f & Son Test Cevapları & f \\
\hline Çok yağmur yağması & 6 & Çok yağmur yağması & 15 \\
Çok su olması & 14 & Çok su olması & 6 \\
Taşkın & 1 & Her şeyi götürmesi & 3 \\
Karların erimesi sonucu & 1 & Taşkı & 2 \\
Hava rüzgarlı ve yağmurlu olduğunda & 1 & Doğal afet & 1 \\
\hline
\end{tabular}

Tablo 1'de öğrencilerin verdiği cevaplara bakıldığında ön testte yağmur ve sudan bahsedilirken son testte selin verdiği etkilerden bahsedilerek selin yıkıcı etkisi ve sonuçları üzerinde durulmuştur. Çalışmaya katılan öğrencilerden bazılarının verdikleri cevaplar şu şekildedir. Örneğin, Ö14 ön testte "Sel Olayı Nedir?” sorusunu boş bırakırken, son testte " Çok yağmur yağınca insanlarla, arabaları götürür." şeklinde cevap vermiştir. Ö19 ön testte “Çok yağmur.", son testte "Sel bir su akıntısının evleri götürmesi." şeklinde yanıtlamıştır.

Tablo 2. Yaz Mevsimi Sembollerinden "Sel Olayı Nasıl Oluşur ?" Sorusuna Verilen Cevaplar

\begin{tabular}{llll}
\hline Ön Test Cevapları & f & Son Test Cevapları & f \\
\hline Çok yağmur yağması sonucu & 12 & Çok yağmur yağması sonucu & 20 \\
Yağmur ile oluşur & 10 & Yağmur ile oluşur & 5 \\
Su baskını sonucu oluşur & 3 & Suların birikip taşkın oluşması & 2 \\
Karların erimesi sonucu & 1 & Karların erimesi & 1 \\
Kanalizasyonlar tıkanarak & 1 & Fırtınadan & 1 \\
Sular birleştiğinde & 1 & & \\
Çok Güneşli havalarda Güneş su toplar & 1 & & \\
\hline
\end{tabular}


Tablo 2’te öğrencilerin verdiği cevaplara bakıldığında "Sel Olayı Nasıl Oluşur ?" sorusuna ön test ve son testte benzer cevapların verildiği görülmüştür. "Çok yağmur yağması sonucu“ ifadesinde ön ve son test arasında uç noktada anlamlı bir fark yoktur.

Tablo 3. Yaz Mevsimi Sembollerinden "Sel Olayı Ne Zaman Oluşur ?” Sorusuna Verilen Cevaplar

\begin{tabular}{llll}
\hline Ön Test Cevapları & f & Son Test Cevapları & f \\
\hline Yağmurlu havada oluşur & 13 & Yağmurlu havada oluşur & 7 \\
Çok yağmur yağınca oluşur & 6 & Çok yağmur yăğınca oluşur & 6 \\
Soğuk havada & 2 & Her an oluşabilir. & 4 \\
Her an oluşabilir. & 2 & Kışın & 2 \\
Kışın & 1 & Sonbahar ve İlkbahar & 2 \\
Sonbahar ve İlkbahar & 1 & Belli olmaz & 2 \\
Belli olmaz & 1 & Sabah & 1 \\
Her an olabilir & 1 & Kanalizasyonlar tıkandığında & 1 \\
& & Rüzgar çıtığında & 1 \\
& & Soğuk havada & 1 \\
\hline
\end{tabular}

Tablo 3'de öğrencilerin verdiği cevaplara bakıldığında "Sel Olayı Ne Zaman Oluşur?” sorusuna verilen yanıtlarda ön test ve son test arasında anlamlı bir azalışın meydana geldiği gözlemlenmiştir.

Tablo 4. Yaz Mevsimi Sembollerinden "Sel Olayı Nerede Oluşur?" Sorusuna Verilen Cevaplar

\begin{tabular}{llll}
\hline Ön Test Cevapları & f & Son Test Cevapları & f \\
\hline Her yerde oluşur. & 14 & Her yerde oluşur. & 9 \\
Yağmur alan yerlerde & 5 & Yağmur alan yerlerde. & 6 \\
Bazı yerlerde & 3 & Akarsu / dere yataklarında & 3 \\
Ağaçsız yerlerde & 1 & Karadeniz'de & 1 \\
İstanbul'da & 1 & Amerika'da & 1 \\
Havada & 1 & Havada & 1 \\
Belli olmaz & 1 & Batıda & 1 \\
Kışın & 1 & Kışın & 1 \\
& & Bazı illerde & 1 \\
\hline
\end{tabular}

Tablo 4'te öğrencilerin verdiği cevaplara bakıldığında “Sel Olayı Nerede Oluşur ?” sorusuna ön test "Her yerde oluşur." şeklinde genel bir cevap verilirken. Son testte verilen cevaplarda "Sel Olay1 Nerede Oluşur?" sorusunu daha iyi açıklayan "Yağmur alan yerlerde" ve "Akarsu/dere yataklarında." cevaplarında artış meydana gelmiştir. Örneğin Ö13 ön testte "Yerde, havada, ağaçlı yerde.” şeklinde cevaplarken, son testte "Karadeniz'de görülür." cevabını vermiştir. Ö3 ön testte "Her yerde görülür." şeklinde cevaplarken, son testte “Akarsu yataklarında.” ş̧eklinde cevaplamıştır. Ö4 kod numaralı öğrenci 
ön testte "Dünyada" cevabını verirken son testte "Sel, fazla yağış alan ve su kenarlarında görülür şeklinde cevap vermiştir.”

Tablo 5. Kış Mevsimi Sembollerinden Kar Yağışı Sembolü Gösterilip "Resimdeki Sembol Nedir?" Sorusuna Verilen Cevaplar

\begin{tabular}{llll}
\hline Ön Test Cevapları & f & Son Test Cevapları & f \\
\hline Kar yağı̧̧ı & 28 & Kar yağı̧ıı & 28 \\
Kış & 1 & Kış & 1 \\
\hline
\end{tabular}

Tablo 5'te öğrencilerin verdiği cevaplara bakıldığında, Kış mevsimi sembollerinden Kar Yağış1 sembolü öğrencilere gösterilip "Resimdeki Sembol Nedir?" sorusuna ön test ve son testte anlamlı bir fark olmadığı, benzer cevapların verildiği görülmüştür

Tablo 6. Kış Mevsimi Sembollerinden “Kar Yağışı Nasıl Oluş̧ur ?” Sorusuna Verilen Cevaplar

\begin{tabular}{llll}
\hline Ön Test Cevapları & f & Son Test Cevapları & f \\
\hline Suların buharlaşıp soğuması sonucu & 15 & Suların buharlaşıp soğuması sonucu & 13 \\
Bulutlardaki suyun birikmesi sonucu & 6 & Yağmur yağdıktan sonra & 3 \\
Yağmur yağdıktan sonra & 2 & Bulutlardaki suyun birikmesi sonucu & 2 \\
Buhar rüzgar esmesi sonucu kara dönüşür & 1 & Hava eksilere geldiğinde & 1 \\
Su damlalarının katı hale gelmesi ile oluşur & 1 & Tanecikler büyür ve buz taneleri oluşur. & 1 \\
Belki az da yağar & 1 & Gök gürültüsüyle oluşur & 1 \\
Kar yağıyor & 1 & Kar kışın oluşur & 1 \\
& & Sonbaharda & 1 \\
& & Bulutlar kararınca kar 1 veya 2 tane atar ve & 1 \\
& & daha yağar & 1 \\
& & Buhardan buz olunca & 1 \\
\hline
\end{tabular}

Tablo 6'da öğrencilerin verdiği cevaplara bakıldığında "Kar Yağışı Nasıl Oluşur ?” sorusuna ön testte ve son testte "Suların buharlaşıp soğuması sonucu" cevabı ağırlık kazanırken, bu bulgular sonucunda 15 gün izleme sonrası sembolün bilinme sayısında azalma olduğu görülmektedir. Ö4 ön testte "Hava soğur buharlaşan suyun bulutlara gitmesi sonucu donup kar olarak yağar." derken, son testte "Su döngüsü olayı" şeklinde cevap vermiştir. Ö11 ise ön testte "Yağmur yağar. Yağmur soğuduğu zaman kar yağar." şeklinde yanıtlarken son testte "Buhardan buz olunca" şeklinde, Ö14 ön testte "Su buharlaşır ve hava soğuduğundan ve yağmur yağınca kar yağar" şeklinde cevap verirken son testte "Yağmur ve rüzgar oluşunca" ifadesini kullanmıştır. 
Tablo 7. Kış Mevsimi Sembollerinden "Kar Yağışsı Ne Zaman Oluşur ?” Sorusuna Verilen Cevaplar

\begin{tabular}{llll}
\hline Ön Test Cevapları & f & Son Test Cevapları & f \\
\hline Hava soğuk olduğunda oluşur & 11 & Kışın oluşur & 13 \\
Kışın oluşur & 10 & Hava soğuk olduğunda oluşur & 9 \\
Güneş gider bulutlar gelirse oluşur & 2 & Yağmur yağınca & 3 \\
Akşam & 2 & Her zaman & 1 \\
Bulutlar birbirine çarpışınca & 1 & Buhar kar olunca & 1 \\
Sabah, öğlen, akşam & 1 & Sabah, öğlen, akşam & 1 \\
Çok kar yağınca & 1 & & \\
O günden sonra yağmayı birakır & 1 & & \\
\hline
\end{tabular}

Tablo 7'de öğrencilerin verdiği cevaplara bakıldığında "Kar Yağışı Ne Zaman Oluşur ?" sorusuna ön test ve son testte "Hava soğuk olduğunda oluşur" ve "Kışın oluşur" cevaplarının ağırlık kazandığ1 görülmüştür. Sonuç olarak iki test arasında anlamlı bir farka rastlanmamıştır.

Tablo 8. Kış Mevsimi Sembollerinden “Kar Yağışı Nerede Görülür?” Sorusuna Verilen Cevaplar

\begin{tabular}{llll}
\hline Ön Test Cevapları & f & Son Test Cevapları & f \\
\hline Havanın soğuk olduğu yerlerde & 8 & Havanın soğuk olduğu yerlerde & 9 \\
Havada görülür & 6 & Havada görülür & 5 \\
Kuzeyde görülür & 3 & Her yerde görülür & 5 \\
Dağlarda görülür & 3 & Kuzeyde görülür & 1 \\
Ormanlık alanlarda & 1 & Kış olan yerlerde & 1 \\
Akşam kar yağarken & 1 & Bir yerlerde & 1 \\
Kapalı hava olduğu zaman & 1 & Gök kararınca & 1 \\
Kar olayı çoğu ilde görülür & 1 & Çoğu ilde görülür & 1 \\
Doğuda kış yaşayan ülkelerde & 1 & Akşam & 1 \\
\hline
\end{tabular}

Tablo 8'de öğrencilerin verdiği cevaplara bakıldığında "Kar Yağışı Nerede Görülür?” sorusuna yukarıdaki tabloda ön test ve son test sonuçlarına bakıldı̆̆ında anlamlı bir farkın olmadığı bulgulanmıştır.

\section{SONUÇ}

Araştırmaya katılan öğrencilerin yaz mevsimine ait hava durumu görsellerine ilişkin ön-son test puanları değerlendirildiği zaman, yaz sel sembolü, yaz parçalı bulutlu sembolü, yaz nemli hava sembolü, yaz bulutlu sembolü, yaz kuru hava sembolü ve yaz güneşli sembolüne ilişkin ön-son test bilgi düzeyleri arasında anlamlı bir farklılık olmadığı tespit edilmiştir. Buna karşılık öğrencilerin ön test ile kıyaslandığ zaman son test yaz yağmur sembolü, yaz sağanak yağış sembolü ve yaz çisenti sembolü bilgi 
düzeylerinde istatistiksel açıdan anlamlı bir artış meydana geldiği tespit edilmiştir. Benzer şekilde tüm sembollere ilişkin bilgi düzeyinde de ön test değerlerine kıyasla son test ölçümlerinde anlamlı bir artış gözlendiği tespit edilmiştir. Elde edilen bu bulgulara göre, eğitim programı sonrasında öğrencilerin yaz mevsimine ilişkin hava durumu sembollerine ait bilgi düzeylerinin genel anlamda yükseldiği sonucuna ulaşılmıştır.

Literatürde yer alan benzer araştırmalarda da farklı öğretim yöntemlerinin öğrencilerin hava durumuna ilişkin bilgi düzeylerini arttırmaya yardımcı olduğu bulgularına ulaşılmıştır. Akbaş ve diğerleri (2012) tarafından yürütülen çalışmada 9. sınıf öğrencilerine iklim ve hava durumu konusunda verilen eğitimlerin iklim ve hava durumu konusundaki bilgi düzeyi üzerindeki etkilerinin incelenmesi amaçlanmış, araştırma kapsamında öğrenciler deney ve kontrol grubu olmak üzere iki gruba ayrılmıştır. Deney grubunda yer alan öğrencilere iklim ve hava durumu bilgi düzeyini geliştirmeye yönelik eğitim programı uygulanmış, bu süreçte kontrol grubunda bulunan öğrenciler hava durumu konusunun ele alındığı herhangi bir eğitim programına katılmamıştır. Araştırmanın sonunda grupların ön test hava durumu ve iklim konusundaki bilgi düzeylerinin benzer seviyede olduğu, buna karşıllk son test ölçümlerinde kontrol grubunda bulunan öğrenciler ile kıyaslandığı zaman deney grubunda yer alan öğrencilerin hava durumu ve iklim konusundaki bilgi düzeylerinde anlamlı bir artış gözlendiği rapor edilmiştir. Bunun yanında yapılan çalışmalarda öğrencilere uygulanan farklı öğretim yöntemlerinin coğrafya konusundaki bilgi düzeyini de geliştirmeye yardımcı olduğu bulgularına ulaşılmıştır (Koçak ve Ünlü, 2013; Çelik, 2007).

Araştırmaya katılan öğrencilerin kış mevsimine ait hava durumu sembollerine ilişkin ön-son test puanları değerlendirildiği zaman, kış tipi sembolü, kış don sembolü, kış hortum sembolü, kış parçalı bulutlu sembolü, kış çiğ sembolü, kış bulutlu sembolü, kış firtına sembolü, kış karla karışık yağmurlu sembolü, kış dolu sembolü, kış kırağı sembolü ve kış tüm semboller ön-son test bilgi düzeyleri arasında anlamlı bir farklılık bulunmadığı tespit edilmiştir. Buna karşılık öğrencilerin ön test ile kıyaslandığı zaman son test bilgi düzeylerinde istatistiksel açıdan anlamlı gelişmelerde gözlendiği belirlenmiştir. Ancak ön test ile kıyaslandığı zaman son test kış gök gürültülü sembolü, kış rüzgar sembolü, kış şimşek sembolü, kış yıldırım sembolü ve kış yağmur sembolü bilgi düzeylerinde anlamlı azalma, kış sis sembolü bilgi düzeylerinde ise anlamlı artış meydana geldiği görülmüştür. Elde edilen bu bulgulara göre öğrencilerin kış mevsimine ilişkin hava durumu sembolü bilgi düzeylerinin genel anlamda artış göstermediği, hatta birçok sembole ilişkin bilgi düzeylerinde azalma görüldüğü sonuçlarına ulaşılmıştır. $\mathrm{Bu}$ sonucun ortaya çıkmasının temelinde öğretim programında kış hava durumu sembollerinin öğretimine ilişkin kullanılan öğretim yöntemlerinin yetersiz olmasının yattı̆̆g düşünülebilir. Yapılan çalışmanın nisan ayında yapılmasının da öğrencilerin kış grafiklerine olan ilgi ve alakanın azalmasına yol açtığı söylenebilir. Coğrafi şartlardan ötürü Erzurum'da yaşayan bir çocuk kış mevsimiyle alakalı 
birçok hava olayını gözlemlerken, Isparta'da yaşayan bir çocuk ise kış ile alakalı bazı hava olaylarını gözlemleme şansına sahip olamayabilir.

Yapılan benzer çalışmalarda da öğrencilere hava durumu sembollerinin öğretiminde kullanılan yöntemlerin bazen yetersiz olduğu, bu nedenle hava durumuna ilişkin öğrenci bilgi düzeyinin yükseltilmesinde farklı öğretim yöntemlerinden yararlanılması gerektiği belirtilmiştir (Doğar ve Başıbüyük, 2005).

\section{KAYNAKÇA}

Akbaş, Y. Koca, H. ve Cin, M. (2008). Ortaöğretim 9. sınıf öğrencilerinin iklim ve hava durumu kavramıla ilgili yanılgılarını gidermede kavramsal değişim yaklaşımının etkinliği. Doğu Coğrafya Dergisi, 17(27), 23-42.

Akçalı, S. İ. (2014). Çocuk ve medya. Ankara: Nobel Akademik Yayıncılık.

Bilgin, N. (2006). Sosyal Bilimlerde İçerik Analizi Teknikler ve Örnek Çalışmalar. (2.Basım) Ankara: Siyasal Kitabevi.

Çelik, E. (2007). Ortaöğretim coğrafya derslerinde bilgisayar destekli animasyon kullanımının öğrenci başarısına etkisi. Yüksek Lisans Tezi. Marmara Üniversitesi Eğitim Bilimleri Enstitüsü. İstanbul.

Doğar, Ç. ve Başıüyük, A. (2005). İlköğretim ve ortaöğretim öğrencilerinin hava ve iklim olaylarını anlama düzeyleri. Kastamonu Eğitim Dergisi, 29, 347.

Ertürk, Y. D. (2011). Çocukluk çağı gelişim dönemlerine göre medya kullanımı. Mustafa Ruhi Şirin (Ed.), Çocuk hakları ve medya el kitabı. (s. 49-84). İstanbul: Çocuk Vakfı.

Geçer, E. (2013). Medya ve Popüler Kültür. İstanbul: Metamorfoz Yayıncılık.

Güneş, F. (2013). Bartın Üniversitesi Eğitim Fakültesi Dergisi 2(1,) 1 - 17. Bartın.

Kocadaş, B. (2005). Medya ve Kültür. Bilig Dergisi. S34. 1-13.

Koçak, M. ve Ünlü, M. (2013). Coğrafya öğretiminde probleme dayalı öğrenme yaklaşımının öğrenci performans1 ve motivasyonu üzerine etkisi. Marmara Coğrafya Dergisi, (28), 526-543.

Postman, N. (2010). Televizyon öldüren eğlence. (O. AKINHAY Çev.). İstanbul: Ayrıntı Yayınları.

RTÜK. (2007). İlköğretim medya okuryazarllğı dersi öğretmen el kitabı. Ankara: RTÜK.

Sipahi, B., Yurtkoru, E.S. ve Çinko, M. (2008). Sosyal Bilimlerde SPSS ile Veri Analizi. İstanbul: BETA.

TUIK, (2015). http://www.tuik.gov.tr/PreTablo.do?alt_id=1038 sayfasından erişilmiştir. 


\section{EXTENDED ABSTRACT}

Introduction: Nowadays, smartphones, televisions, computers, etc. With the technological tools, we have a short knowledge of the weather related to our location. As of 2015 in television programming and broadcasting activities 481 institutions in Turkey, the radio broadcasting as a total of 787 institutions in 1268 are an enterprise engaged in programming and broadcasting activities (TUIK, 2015). Many of the media channels feature weather bulletins in broadcasts. Various visuals are used in weather bulletins to describe weather events.It is an image emerging from an original model, regardless of whether it is visual, real or imaginary. In other words, an image is an imitation of a reality, an image that allows us to recognize something unreal, an overall representation of an object or sign. It is very easy to create mental images and visualize some events in mind dimension through visuals. The visual reading phase is a phase that organizes and configures the mind. In this phase, students better organize and configure their mental images related to a concept or topic (Güneş, 2013).In this study, it was tried to determine the perceptions of third grade students' weather symbols in visual media.

Method: In the research, the mixed method was used considering the qualitative and quantitative data. In the collection of qualitative data, the student observation form, which was created by taking expert opinion, was used. First of all, the pretest application consisting of summer and winter period symbols was applied to the student group on different days. Following the written consent of the parents, the children were asked to watch the weather bulletin in the news zone on the TRT Children's channel for 15 days. At the end of each day they watched, it was informed that parents and students could cooperate and after 15 days, a post-test was applied. Written responses in the pre-test and post-test were transferred to the computer environment by the researcher and scored by 3 field experts, and the Cronbach Alpha coefficient value was calculated as 0.829 regarding the reliability of the scoring. The analysis of the data was done with the SPSS Version 22 program. Content analysis method was used to analyze the data.

Results and Conclusion: When the pre-post test scores of the students who participated in the research related to the summer weather are evaluated, the pre-post test information about the summer flood symbol, the summer split cloudy symbol, the summer moist weather symbol, the summer cloudy symbol, the summer dry weather symbol and the summer sunny symbol There was no significant difference between the levels. On the other hand, when compared with the pre-test, it was determined that there was a statistically significant increase in the post-test summer rain symbol, summer torrential rainfall symbol and summer drizzle symbol knowledge levels. Similarly, a significant increase was observed in the post-test measurements compared to the pretest values at the level of knowledge of all symbols. According to these findings, it was concluded that, after the education program, the knowledge levels of students' weather symbols related to the summer season increased in general. 